\title{
Um olhar sobre a condição feminina no filme Roma
}

\author{
Una mirada a la condición femenina en la película Roma
}

\author{
A look at the female condition in the movie Roma
}

Isadora Ebersol ${ }^{1}$

Ana Paula Penkala ${ }^{2}$

\begin{abstract}
Resumo
Tendo como pano de fundo as revoltas políticas do início dos anos de 1970 na Cidade do México, Roma (Alfonso Cuarón, 2018) acompanha a vida de uma família de classe média a partir de uma personagem central: Cleo, a babá e empregada doméstica que trabalha para a família. As vidas de Cleo, de origem indígena e Sofia, a patroa branca, são conectadas pela experiência da solidão feminina, do cotidiano doméstico e familiar, da maternidade e do abandono masculino, embora se distanciem profundamente pelo contraste social que demarca uma fronteira simbólica entre as duas. Este trabalho busca analisar a condição feminina a partir destas duas personagens centrais do filme, considerando tanto a condição que compartilham enquanto mulheres dentro de uma mesma estrutura de dominação patriarcal, como também a situação específica vivida por cada uma dentro desta sociedade, balizada por diferenças de raça e classe. $\mathrm{O}$ fio condutor da narrativa se apoia nesse movimento de costura entre as diferenças e semelhanças das duas personagens e as formas específicas como sintetizam e materializam a condição feminina. Buscamos analisar visualmente e narrativamente como se constroem estes contrastes a partir das interações íntimas e produções cotidianas das personagens entre si e com o espaço. Partimos de uma leitura decolonial que busca evidenciar a continuidade e atualização das formas de dominação coloniais, cuja base é a divisão racial do trabalho e o poder patriarcal, e que deixam profundas marcas na experiência vivida pelas mulheres latino-americanas.
\end{abstract}

Palavras-Chave: Cinema; decolonial; feminino; mulheres; Roma.

\section{Resumen}

En el contexto de las revueltas políticas de principios de la década de 1970 en la Ciudad de México, Roma (Alfonso Cuarón, 2018) sigue la vida de una familia de clase media de un personaje central: Cleo, la niñera y la criada que trabaja para la familia. Las vidas de Cleo, de origen indígena y Sofía, la jefe blanca, están conectadas por la experiencia de la soledad femenina, la vida cotidiana doméstica y familiar, la maternidad y el abandono masculino, aunque están profundamente distanciadas por el contraste social que marca un límite simbólico entre las dos mujeres. Este texto busca analizar la condición femenina de estos dos personajes centrales de la película, considerando tanto la condición que comparten como mujeres dentro de la misma estructura de dominación patriarcal, como la situación específica que experimenta cada una dentro de esta sociedad, marcada por diferencias de raza y clase. El hilo conductor de la narrativa se basa en este movimiento de costura entre las diferencias y similitudes de los dos personajes y las formas específicas en que sintetizan y materializan la condición femenina. Buscamos analizar visual y narrativamente cómo se construyen estos contrastes a partir de las interacciones íntimas y las producciones diarias de los personajes entre sí y con el espacio. Partimos de una lectura decolonial que busca resaltar la continuidad y actualización de las formas coloniales de dominación, basadas en la división racial del trabajo y el poder patriarcal, y que dejan profundas huellas en la experiencia vivida por las mujeres latinoamericanas.

Palabras claves: Cine; decolonial; femenino; mujeres; Roma.

\footnotetext{
Abstract

${ }^{1}$ Mestre em Artes Visuais; Pesquisadora do Grupo Interdisciplinar de Pesquisa: Narrativas, Arte, Linguagem e Subjetividade - GipNals/UFPel; Pelotas, Rio Grande do Sul, Brasil; isadora.ebersol@gmail.com)

${ }^{2}$ Doutora em Comunicação e Informação pela UFRGS; Professora adjunta dos cursos de Cinema e de Design da Universidade Federal de Pelotas; Pelotas; Rio Grande do Sul; Brasil; penkala@ gmail.com
} 
Having in the background the political revolts of the early 1970s in Mexico City, Rome (Alfonso Cuarón, 2018) follows the life of a middle-class family from a central character: Cleo, the nanny and maid who works for the family. The lives of Cleo, of indigenous origin and Sofia, the white mistress, are connected by the experience of female loneliness, domestic and family daily life, motherhood and male abandonment, although they are deeply distanced by the social contrast that marks a symbolic boundary between the two women. This paper seeks to analyze the female condition from these two central characters of the film, considering both the condition they share as women within the same structure of patriarchal domination, as well as the specific situation experienced by each within this society, marked by differences of race and class. The thread of the narrative rests on this movement of sewing between the differences and similarities of the two characters and the specific ways in which they synthesize and materialize the feminine condition. We seek to analyze visually and narratively how these contrasts are constructed from the intimate interactions and daily productions of the characters with each other and with the space. We start from a decolonial reading that seeks to highlight the continuity and updating of colonial forms of domination, based on the racial division of labor and patriarchal power, and which leave deep marks on the experience lived by Latin American women.

Keywords: Cinema; decolonial; feminine; women; Rome.

\section{Introdução}

Ao analisar a acumulação primitiva e o desenvolvimento capitalista, Silvia Federici (2017) afirma que Marx nunca presumiria que o capitalismo seria um processo que criaria condições materiais necessárias à libertação humana se tivesse analisado seu desenvolvimento pelo ponto de vista das mulheres. As mulheres, segundo Federici, foram exploradas de modos similares aos da escravidão, o que implicaria o dever de olhar para a história através de um ponto de vista feminino que permita tornar visíveis as estruturas ocultas de dominação e exploração. Debruçar-se sobre estas estruturas não é, com efeito, um trabalho novo para a teoria feminista que desde o início tem a transição para o capitalismo como uma questão basilar para compreender as raízes da opressão das mulheres. Sob o ponto de vista destas análises, a exploração das mulheres desempenhou uma função central no desenvolvimento do capitalismo ao lhes atribuir, através do uso de seus corpos e condição reprodutiva, a reprodução do seu bem mais valioso - a força de trabalho - ao mesmo tempo em que a mistifica como um destino biológico e uma condição de ordem pessoal, não reconhecendo-a como fonte da acumulação de capital. Não só a reprodução humana calcada no trabalho não remunerado da maternidade foi central para o desenvolvimento do capitalismo, como a reprodução material da vida cotidiana, o trabalho doméstico, permitiu que o modo de vida capitalista se sustentasse.

Roma (2018), filme do diretor mexicano Alfonso Cuarón, tem nos eixos da maternidade e do trabalho doméstico duas importantes chaves para compreender a condição feminina pós-colonial. Tendo como pano de fundo as revoltas políticas do início dos anos de 1970 na Cidade do México, Roma acompanha a vida de uma família de classe média a partir de uma personagem central: Cleo, a babá e empregada doméstica que trabalha para a família. 
O filme tem inspiração autobiográfica e reúne tanto as memórias do diretor sobre a situação política e social do país daquela época com o início do governo de Luís Echeverría, como, sengundo o próprio Cuarón, seria uma homenagem à babá ameríndia de origem mixteca que trabalhou na casa da sua família durante sua infância, Libória Gutiérrez.

O filme acompanha a dissolução do casamento da mãe da família, Sofia, quando o marido abandona ela e seus quatro filhos sem qualquer explicação ao mesmo tempo em que Cleo é abandonada grávida. As vidas de Cleo e Sofia são conectadas pela experiência da solidão feminina, do cotidiano doméstico e familiar, da maternidade e do abandono masculino, embora se distanciem profundamente pelo contraste social que demarca uma fronteira simbólica entre as duas. Este trabalho busca analisar a condição feminina a partir destas duas personagens centrais do filme, considerando tanto a condição que compartilham enquanto mulheres dentro de uma mesma estrutura de dominação patriarcal, como também a situação específica vivida por cada uma dentro desta sociedade, balizada por diferenças de raça e classe. O que faz destas duas mulheres semelhantes entre si e o que as diferencia? A antropóloga mexicana Marcela Lagarde y de los Rios põe questões semelhantes ao elaborar sua antropologia da mulher em Los cautiverios de las mujeres: madresposas, monjas, putas, presas y locas (2005), onde sintetiza seu trabalho com centenas de mulheres de diferentes idades, classes sociais e tradições culturais entre os anos de 1983 a 1988 nos estados do México, Puebla e Distrito Federal no México. Para Lagarde “[...] as mulheres são diversas e diversos são seus cativeiros" (2005, p. 38, tradução nossa ${ }^{3}$ ), e ainda que compartilhem os cativeiros de sua condição, será a situação concreta de vida de cada uma que definirá os níveis de sua opressão.

Ainda que todas as mulheres sofram a opressão de gênero (todas as mulheres estão cativas, independente de sua consciência sobre os limites de seu/seus cativeiros), há uma diferença entre a condição histórica da mulher, definida pelo “[...] conjunto de circunstâncias, qualidades e características essenciais que definem a mulher como ser social e cultural" (LAGARDE, 2005, p.77, tradução nossa ${ }^{4}$ ) e a situação da mulher que refere-se à existência concreta das mulheres a partir de sua condição real de vida. Para Lagarde (2005, p. 102, tradução nossa ${ }^{5}$ ), as mulheres trabalhadoras sofrem uma dupla opressão pela síntese da “[...] forma específica que o capital-patriarcal oprime por seu gênero e sua classe as mulheres

\footnotetext{
${ }^{3}$ No original: "[...] las mujeres son diversas y diversos sus cautiverios."

${ }^{4}$ No original " [....] conjunto de circunstancias, cualidades y características esenciales que definen a la mujer como ser social y cultural genérico."

${ }^{5}$ No original: "[...] forma específica en que el capital-patriarcal oprime por su género y su clase a las mujeres explotadas."
} 
exploradas”. As mulheres negras e indígenas sofrem, ainda, uma tripla opressão pela síntese de diversos núcleos de relações opressivas em um mundo classista, racista e patriarcal.

O fio condutor da narrativa de Roma apoia-se nesse movimento de costura entre as diferenças e semelhanças das duas personagens e as formas específicas como sintetizam e materializam a condição feminina. Buscamos analisar visualmente e narrativamente como se constroem estes contrastes a partir das interações íntimas e produções cotidianas das personagens entre si e com o espaço. Buscamos ainda problematizar a questão da produção masculina ao representar o universo e questões femininas.

Para além do discurso do progresso, a modernidade, segundo autores como Walter D. Mignolo (2017) e Aníbal Quijano $(2005,2009)$ esconde seu lado mais cruel, a negação e o desperdício de vidas humanas. A lógica da modernidade colonial, portanto, é outra importante chave de análise de Roma, uma vez que a violência colonialista e capitalista apoiada na classificação da população mundial a partir da ideia de raça funcionou como categoria mental da modernidade e foi um dos instrumentos de dominação social mais eficazes e duráveis da colonialidade, junto com as categorias sexual e de gênero, todas baseadas em uma suposta inferioridade natural e biológica dos sujeitos dominados. $\mathrm{O}$ padrão mundial capitalista como novo sistema de relações de produção e de controle de trabalho apenas pôde consolidar-se e adquirir predominância mundial após a colonização da América Latina. O capitalismo tem, portanto, uma ligação íntima com o colonialismo e mesmo com o fim do período colonial nas américas, formas de dominação coloniais ainda persistem. Partimos de uma leitura decolonial que busca evidenciar a continuidade e atualização das formas de dominação coloniais, cuja base é a divisão racial do trabalho e o poder patriarcal, e que deixam profundas marcas na experiência vivida pelas mulheres latino-americanas.

\section{A herança colonial e o trabalho doméstico}

Se o capitalismo pôde se desenvolver e se fixar como padrão de poder mundial, foi a colonização e constituição histórica das Américas a condição para que isso ocorresse. Aníbal Quijano demonstra que não haveria capitalismo sem o colonialismo e a América foi "o primeiro espaço/tempo de um padrão de poder de vocação mundial" (QUIJANO, 2005, p. 107) e que, por isso, se constituiu como a primeira identidade da modernidade. Não haveria um sistema capitalista mundial, portanto, sem o genocídio, a expropriação, e a consequente conquista da América (em especial a latina) pelos povos europeus, assim como não haveria modernidade sem colonialismo (QUIJANO, 2005, MIGNOLO, 2017). 
Esse padrão de poder capitalista colonial/moderno teve na ideia de raça uma importante e durável ferramenta de controle social. Segundo Quijano, a ideia de raça como categoria mental da modernidade criou-se e mundializou-se a partir da América pela forma como os colonizadores sintetizaram e hierarquizaram as diferenças fenotípicas entre eles e os povos não-europeus. A consequente criação de identidades sociais historicamente novas como os negros, índios e mestiços, foi a forma como os colonizadores europeus puderam legitimar e naturalizar as relações de dominação dos povos não-europeus durante a conquista, baseandose em uma suposta inferioridade natural desses povos. As novas relações que se estabeleceram a partir dessa classificação não só apoiavam-se nas diferenças físicas dos povos ameríndios e de outros povos colonizados, como, por serem fundamentalmente relações de dominação, estabeleceram a inferiorização de suas culturas, de seus traços físicos, de seus conhecimentos, atribuindo-lhes papéis sociais, lugares e hierarquias distintas na estrutura global de poder.

Um segundo eixo fundamental do novo padrão de poder foi, ainda segundo Quijano, a articulação de todas as formas de controle de trabalho anteriormente conhecidas, dos seus produtos e recursos, em torno do capital e visando o mercado mundial:

\footnotetext{
Incluíram-se a escravidão, a servidão, a pequena produção mercantil, a reciprocidade e o salário. Em tal contexto, cada umas dessas formas de controle do trabalho não era uma mera extensão de seus antecedentes históricos. Todas eram histórica e sociologicamente novas. Em primeiro lugar, porque foram deliberadamente estabelecidas e organizadas para produzir mercadorias para o mercado mundial. Em segundo lugar, porque não existiam apenas de maneira simultânea no mesmo espaço/tempo, mas todas e cada uma articuladas com o capital e com seu mercado, e por esse meio entre si. (QUIJANO, 2005, p. 108)
}

Esses dois eixos fundamentais, raça e controle do trabalho, articulam-se e reforçam-se mutuamente parecendo estar naturalmente associados, criando, assim, uma sistemática divisão racial do trabalho em torno do capital que, não por acaso, persiste nas relações de produção atuais. A análise de Quijano nos aponta, com isso, a indissociabilidade da racialização da população e da exploração capitalista do trabalho que deu início a um sistema de poder que perdura até hoje, chamado por ele de colonialidade do poder. Colonialidade passa a ser um conceito central para compreender a atualização e continuidade das formas de poder engendradas durante o período colonial nas Américas, e que perduram mesmo após seu fim como sistema econômico e político de exploração/dominação. Apesar de ter origem e caráter colonial, a colonialidade provou ser mais duradoura e estável que o colonialismo (QUIJANO, 2005, 2009). 
O trabalho doméstico racializado é um dos elos que une a sociedade colonial à atual, perpetuando as relações de poder engendradas no colonialismo. Esta discussão é central em Roma, que tem na protagonista Cleo, de origem indígena e pobre, uma lente que nos permite pensar os diferentes aspectos da relação entre raça, classe e gênero em uma sociedade latinoamericana onde o trabalho doméstico remunerado é exercido primordialmente por mulheres pobres, negras e indígenas, na maioria das vezes, inclusive, sem direitos trabalhistas assegurados. É importante destacar que tanto o trabalho doméstico remunerado quanto o chamado trabalho doméstico não-remunerado ou invisível é realizado por mulheres e ocupam uma grande parte da energia e força vital dessas mulheres, que têm o tempo para se dedicarem a outros aspectos de suas vidas drasticamente afetado, aumentando, assim, os efeitos da opressão patriarcal sobre sua existência. A reprodução da vida cotidiana refere-se a todas as atividades necessárias à manutenção da vida para a sobrevivência em sociedade, como limpar, cozinhar, cuidar das crianças e da casa; e é central para a reprodução do sistema capitalista, uma vez que permite aos trabalhadores, em geral homens, venderem sua força de trabalho ao sistema e produzir para ele. Assim, "no capitalismo mundial, são a questão do trabalho, da 'raça' e do 'género', as três instâncias centrais a respeito das quais se ordenam as relações de exploração/dominação/conflito" (QUIJANO, 2009, p. 104).

Na rotina da família de classe média onde trabalha, Cleo é a primeira a acordar e a última a apagar as luzes, antes de se dirigir, com sua colega Adela, para o quartinho mal iluminado onde as duas moram, um anexo da casa principal. Lá as duas evitam acender as luzes porque a patroa não gosta. O cotidiano doméstico é incessante e se reproduz de forma tão infinita quanto as fezes do cão da família no pátio e as roupas que lava no terraço, lugar ocupado exclusivamente por trabalhadoras domésticas de origem indígena, como mostra a figura 1. É um lugar, no interior das famílias burguesas de classe média e alta, marcadamente racializado e gendrado, assim como também o são o quarto de empregada e a cozinha.

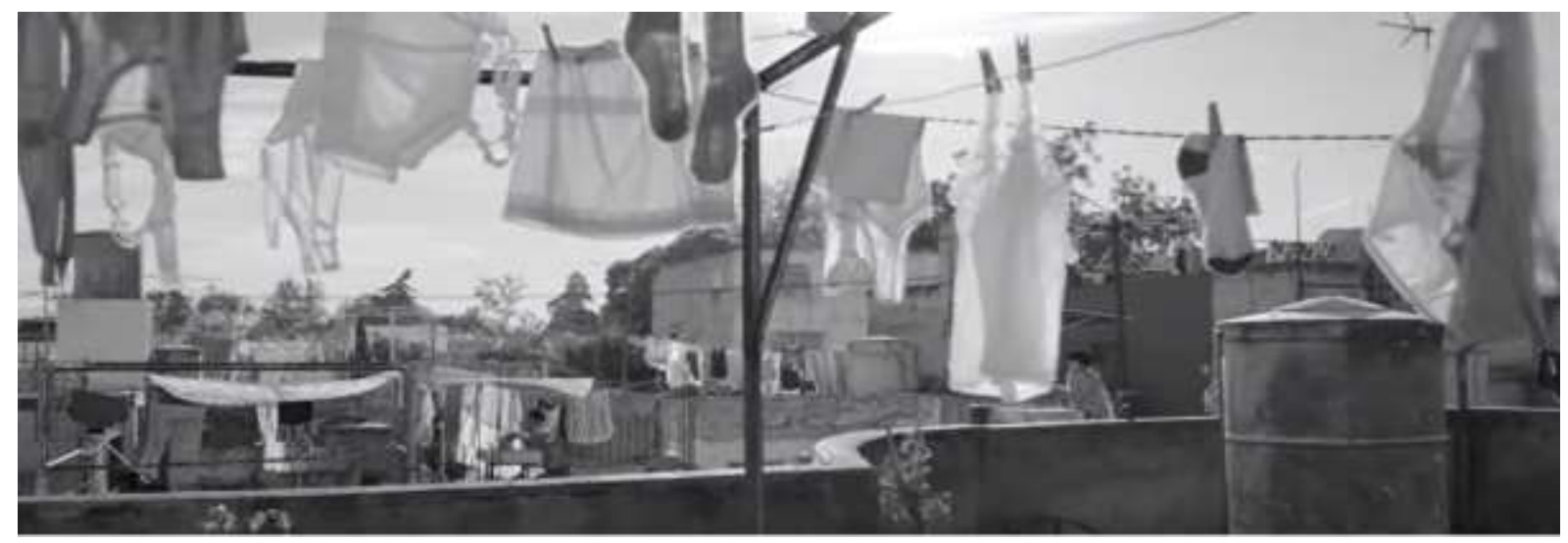

Figura 1 - Terraço das outras casas, ocupados por trabalhadoras domésticas de origem indígena ao fundo. Fonte: Captura de tela do filme. 
A relação de Cleo com a família, em especial com a mãe/patroa, Sofia, e com as crianças, se complexifica para além do caráter laboral, pois inclui uma dimensão de afeto que mascara, por vezes, o lugar subalterno que Cleo ocupa naquela relação. Cleo é considerada praticamente da família, no entanto este "praticamente" é tão concreto quanto evidente em diversas cenas em que sua função social na família e o abismo de classe/raça fica visível. Na cena em que Cleo tem sua bolsa gestacional rompida e precisa ir às pressas para o hospital parir, ela está acompanhada apenas pela avó da família, Teresa. Ao mesmo tempo em que o filme retrata o cuidado que Teresa tem com Cleo durante o engarrafamento que enfrentam até o hospital - a cena transcorre durante o que ficou conhecido como Massacre de Corpus Chirsti $^{6}$ - deixa também evidente que ela pouco sabe sobre a mulher que trabalha na sua casa quando precisa preencher sua ficha de entrada no hospital, em que diz não saber seu segundo nome, nem sua idade, nem data de nascimento.

Ao ser abandonada grávida por Fermin, com quem teve uma breve relação, o lugar subalterno de Cleo faz com que ela experiencie a solidão feminina em um nível ainda mais nefasto, pois está longe de sua mãe e família, não tem posses, nem para onde ir e ainda corre o risco de ser despedida, medo que fica evidente na sua relutância em contar da gravidez à patroa. Cleo, no entanto, é acolhida por Sofia, mas sua gravidez sempre fica em segundo plano frente aos problemas que a família está enfrentando ou mesmo frente às tarefas domésticas e necessidades de todos. Fica evidente, assim, a desproporção entre a humanidade da empregada e sua condição instrumental, tanto dentro da uma lógica capitalista e colonial, quanto considerando-se seu papel na estrutura patriarcal. Em determinada cena, ao acompanhar Sofia e as crianças em uma viagem, Cleo, mesmo grávida, é colocada a carregar todas as malas, o que não é enfrentado pela personagem como um problema, já que ela se mostra todo o tempo como uma personagem servil, doce e resiliente, aspecto de sua construção que iremos abordar com mais atenção em outro momento do texto.

Cleo enfrenta o parto assim como passa o resto do filme: sozinha e impotente. Acima de tudo, passiva, recebendo nessa condição o que o destino lhe reserva sem participar desse processo. A criança nasce morta e à Cleo resta apenas acompanhar os esforços infrutíferos dos médicos em salvar a bebê e desfrutar dos poucos segundos com a sua filha nos braços para,

\footnotetext{
${ }^{6}$ Conhecido também como "El halconazo", o Massacre de Cospus Christi foi o assassinato de manifestantes durante um protesto estudantil ocorrido na Cidade do México em 10 de junho de 1971, dia do festival de Corpus Christi. A manifestação de estudantes contra o governo de Luis Echeverría Álvarez foi reprimida por um grupo de milícia paramilitar chamado de "Halcones" (falcões, em português) formado por jovens, grande parte de origem pobre, treinados pelo governo. Esse incidente foi retratado em Roma e coincide com o momento em que Cleo entra em trabalho de parto, ficando presa em meio ao protesto e engarrafamento. Fermim, pai de sua filha e que a abndonou grávida, faz parte do grupo dos Falcões e participa do massacre.
} 
então, a criança ser levada pelas mãos da equipe do hospital logo em seguida, em um plano sequência de enquadramento único e sutis movimentos panorâmicos que transmite a noção de aprisionamento e impotência da personagem, mais uma vez, frente ao próprio destino (figura 2).

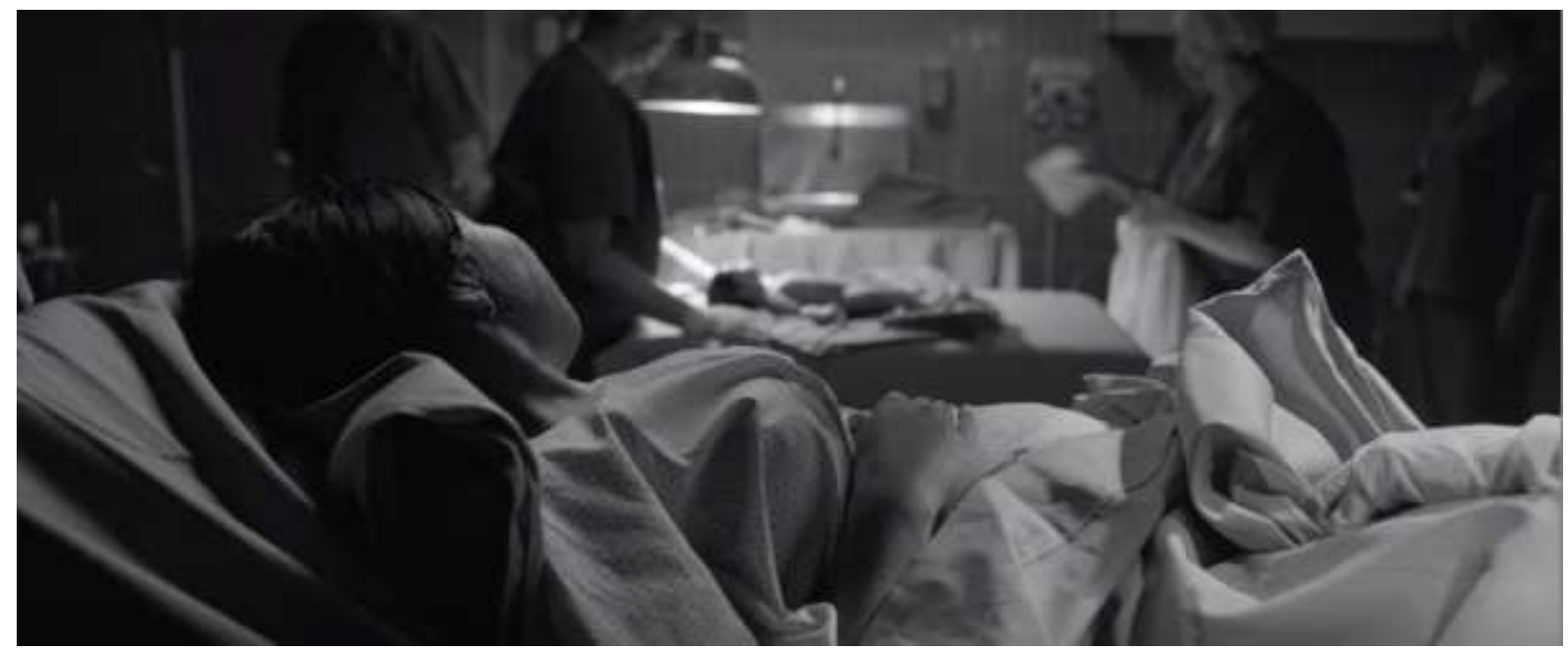

Figura 2 - Parto de Cleo.

Fonte: Captura de tela do filme.

Logo após a sequência do parto, ainda segurando a barriga e sem oportunidade para elaborar nenhum dos acontecimentos, a maternidade e o luto, é convidada por Sofia para uma viagem à praia com as crianças. Cleo tenta negar, no entanto o argumento de que as crianças sentirão sua falta acaba convencendo-a a ir, afinal, entende também que não tem escolha. A promessa é de que irá de folga, no entanto novamente os contornos do afeto moldam e mascaram sutilmente a relação de dominação, já que Cleo cuida das crianças durante toda a viagem, silenciando a dor da perda recente da filha e a culpa por não desejar a criança. Sua humanidade torna a ser assimilada por sua condição de uso, pois "serve para" cuidar das crianças, da família e da manutenção da casa, esteja esta casa onde estiver.

Durante a viagem, Cleo fica sozinha e responsável pelas crianças na ida à praia. A abnegação e devoção à família é tão grande que, mesmo sem saber nadar, arrisca sua vida entrando no mar para salvar duas das crianças de afogarem-se. A sequência termina com um abraço coletivo da família em torno de Cleo que, num momento catártico, confessa que não queria a filha que carregava, evidenciando, com isso, a culpa que carrega por sentir-se responsável pela morte da criança. Para Marcela Lagarde (2005), mesmo quando os filhos morrem, a maternidade dura toda a vida para a mulher. A situação de classe determina ainda o conteúdo específico dessa maternidade que, nessas condições,

É um espaço de exploração e opressão sofrido na intimidade das mulheres; significa a dor e a impotência de ver a seus filhos morrerem, sem que esteja em suas mãos a possibilidade de evitá-lo, mas com a ideologia de que a vida de seus filhos é sua 
responsabilidade. A mãe morre de raiva e culpa, de sofrimento, perante a gravidade e morte de sua criatura, porque de todas as maneiras ainda o luto da maternidade está no centro de seu ser. (LAGARDE, 2005, p. 373, grifo no original, tradução nossa $\left.{ }^{7}\right)$

A composição visual da cena com Cleo no centro e a família em sua volta (figura 3) contrasta com outros momentos do filme em que fica evidente, de forma visual e simbólica, que não há lugar para Cleo ocupar naquela família.

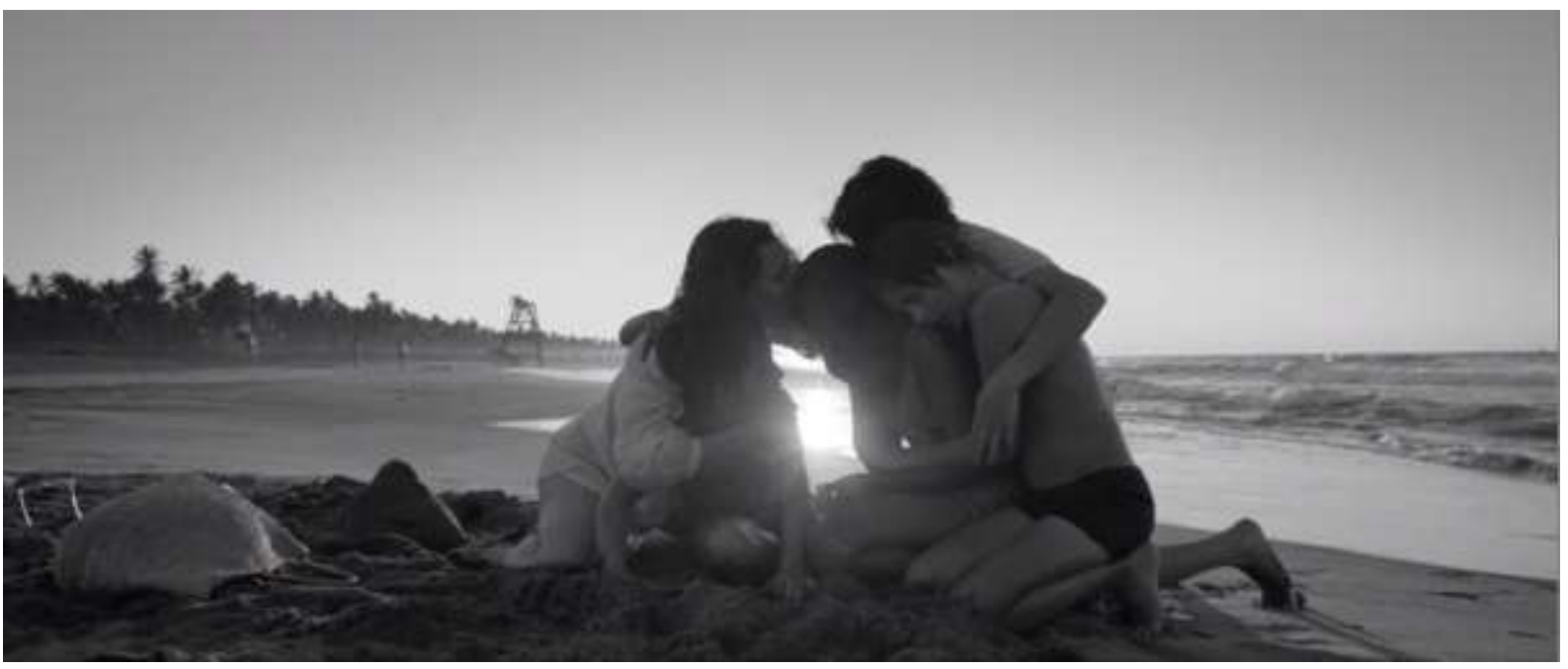

Figura 3 - A família abraça Cleo, que se encontra no centro.

Fonte: Captura de tela do filme.

Seu lugar será sempre o de um apêndice cuja função, por mais que se doe e até receba certo reconhecimento, não é valorizada como de um ser humano, possuidor de dores, necessidades e vontades próprias. É o que fica evidente na distribuição espacial do plano em que Cleo assiste televisão com a família e senta no chão, enquanto todos estão sentados no sofá (figura 4).

\footnotetext{
${ }^{7}$ No original: "[...] es un espacio de explotación y opressión sufrido en la intimidad de las mujeres; significa el dolor y la impotencia de ver a sus hijos morir, sin que esté en sus manos la posibilidad de evitarlo, pero con la ideología de que la vida de sus hijos es su responsabilidad. La madre muere de rabia y culpa, de sufrimiento, ante la gravedad y la muerte de su criatura, porque de todas maneras aun la maternidad doliente está en el cientro de su ser."
} 


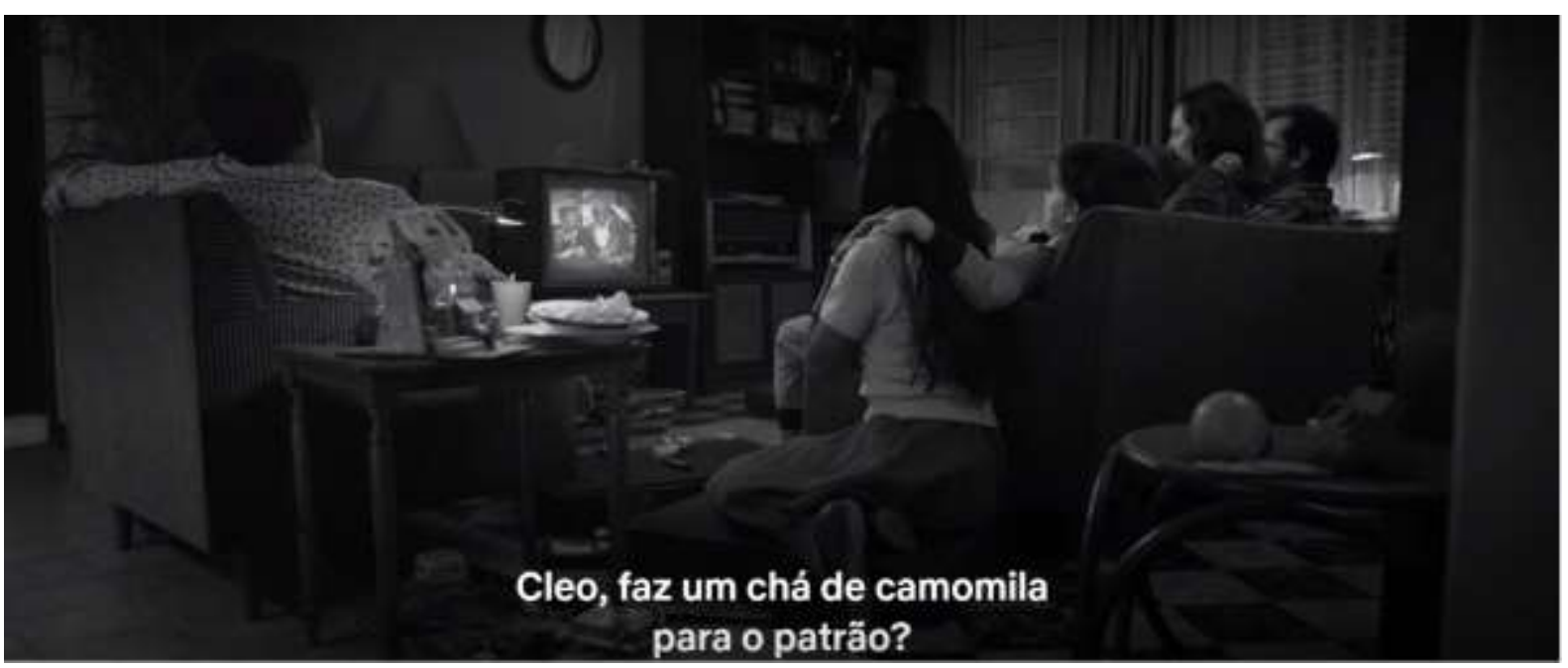

Figura 4 - Cleo senta no chão para assistir televsisão.

Fonte: Captura de dela do filme

A dimensão afetiva está presente no braço que uma das crianças coloca em volta de Cleo quando ela senta-se no chão ao seu lado, para, passados apenas alguns segundos depois de acomodar-se, ter de levantar, pois a patroa lhe pede que faça um chá para o marido. Uma construção visual semelhante se dá durante à viagem a praia quando, após Sofia revelar às crianças que o pai não voltará mais para casa, todos sentam-se num banco em frente ao restaurante para tomar sorvete. Novamente nesse plano, Cleo, que participa de todos esses momentos e dá sustentação à família, se encontra tomando o sorvete de pé olhando o horizonte, enquanto ninguém parece reparar na sua presença ou desconforto (figura 5).

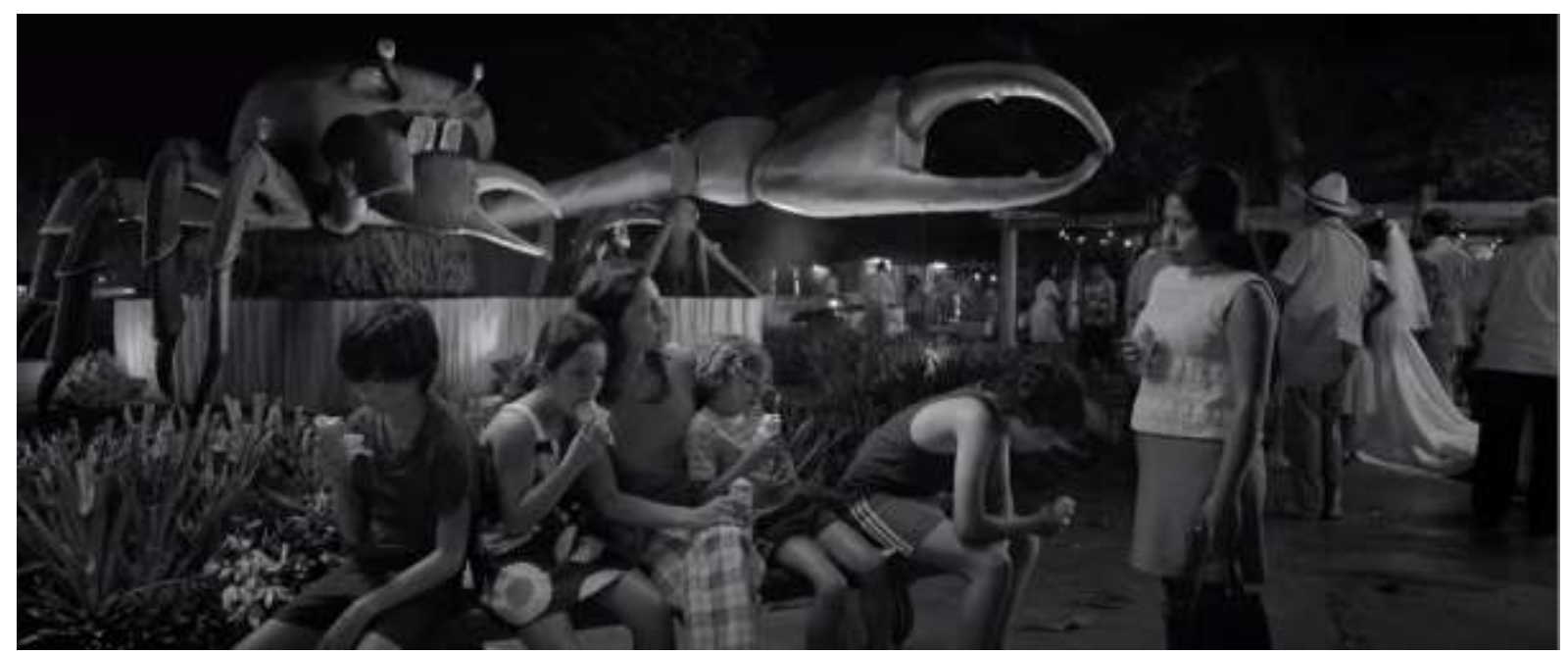

Figura 5 - Cleo toma sorvete em pé enquanto todos estão sentados. Fonte: Captura de dela do filme

Ao chegarem em casa após a viagem à praia, Cleo imediatamente começa a recolher roupas sujas e lençóis, atender o telefone e arrumar a casa. Nesse momento, uma das crianças conta à avó que quase se afogou e que Cleo havia salvado sua vida, para logo em seguida pedir: “Cleo, me faz uma vitamina?”. Não importa, portanto, o quão importante seja seu papel dentro da família ou o quanto de afeto compartilhe com ela, o que Roma evidencia é a herança 
que segue imutável e perpetuando no presente as relações de poder de um passado colonial que tem no trabalho doméstico a imagem síntese dessa sociedade classista, racista e patriarcal escondida por baixo de relações supostamente afetuosas e justas.

\section{Me gusta estar muerta: a mulher não branca como ser impossível}

A impossibilidade de ocupar um lugar de importância na casa, na família e, a um nível de análise mais simbólico, na própria sociedade, soma-se à construção de Cleo como uma personagem sem voz, sem agência sobre seu destino e sua vida e sem camadas de subjetividade que nos permitiriam compreender mais sobre sua situação, sua história, o que pensa e como se vê. Compete-nos perguntar, sem talvez chegar a uma resposta definitiva neste momento, se esse não agenciamento e se esse silêncio são propositais na construção da personagem, a fim de denunciar o silenciamento de pessoas em situação de subalternização, ou se refletem o lugar marcadamente masculino, branco e ocupante das classes superiores do diretor ao construir a personagem. O certo distanciamento na construção de Cleo pode ser compreendido como resultado da dificuldade de Cuarón para superar e transpor esse lugar ao retratar uma realidade que não conhece de forma profunda. Vale ressaltar que a representação da servitude, docilidade e submissão é um lugar comum tanto na representação da figura indígena quanto feminina no cinema. Com isso, Cleo parece corresponder à visão colonizadora sobre o colonizado, em que este, além de não falar, não pensa ou age sobre sua condição. Mesmo sendo a protagonista e o ponto de vista sob o qual a narrativa deveria se construir, não sabemos quase nada a seu respeito. Essa circunstância, em que Cuarón se encontra ainda que inadvertidamente, nos é esclarecida pelo menos desde os anos 60, quando Glauber Rocha faz seu Manifesto da Estética da Fome. Em trecho do texto, o cineasta brasileiro usa um conceito que aqui pode se aplicar a toda a lógica hierárquica de classe, raça e sexo: nostalgia do primitivismo. A construção de Cleo se dá, ainda que sob os efeitos de uma memória afetiva (e, por ela mesma, tão amenizada), sob um olhar que a coloca em seu lugar na estrutura capitalista colonialista e patriarcal. Cleo é como se fosse uma força da natureza, um animal exótico, uma visão bucólica sintetizadora de sua etnia "tribalizada", sua classe subalternizada, sua condição reprodutiva primitivizada.

Para o observador europeu os processos de criação artística do mundo subdesenvolvido só interessam na medida que satisfazem sua nostalgia do primitivismo; e este primitivismo se apresenta híbrido, disfarçado sob as tardias heranças do mundo civilizado, heranças mal compreendidas, porque impostas pelos condicionamentos colonialistas. A América Latina, inegavelmente, permanece colônia, e o que diferencia o colonialismo de ontem do atual é apenas a forma aprimorada do colonizador: e, além dos colonizadores de fato, as formas sutis daqueles que também sobre nós armam futuros botes. O problema internacional da 
América Latina é ainda um pouco de mudança de colonizadores, sendo que uma libertação possível estará sempre em função de uma nova dependência. (ROCHA, $1965, \mathrm{~s} / \mathrm{p})^{8}$

A partir de um outro viés de análise, podemos compreender uma situação proposital construída por Cuarón para evidenciar como a sociedade vê as trabalhadoras domésticas de origem indígena na realidade mexicana e como, para além de efetivamente não terem voz, são produzidas como inexistentes e não humanas na estrutura de poder colonial/patriarcal. A problemática do pensamento decolonial é entender que aqueles e aquelas que estão invisibilizados não o são por uma condição natural, mas foram produzidos como invisíveis por essa mesma estrutura, privados da agência sobre seus destinos, privados do domínio do conhecimento formal, da cultura, da sua língua nativa e dos meios e condições de sobrevivência. Não há um esforço da família, por exemplo, em compreender a língua mixteca, a qual Cleo compartilha apenas nas interações com sua colega de trabalho, Adela. Em um momento do filme, uma das crianças questiona Cleo enquanto ela fala em mixteco, dizendo "O que estão falando? Não fala assim", o que sugere que o filme, mesmo que de forma sutil, contorna essas questões.

Um outro momento simbólico que reflete essa condição é quando dois dos meninos brincam com armas de brinquedo no terraço da casa onde Cleo lava as roupas. Um dos meninos é excluído da brincadeira pelo irmão maior, com o argumento de que era ele quem deveria morrer. O menino, então, deita-se em uma estrutura de concreto de olhos fechados e quando Cleo lhe pergunta o que aconteceu e insiste, perguntando se ele não vai falar, ele responde: "não posso, estou morto". Nesse momento Cleo deita-se como o menino, e quando ele insiste para que ela lhe diga o que está fazendo, Cleo responde: "não posso, estou morta" e complementa: "gosto de estar morta". Este pequeno momento da narrativa talvez nos forneça pistas para compreender a situação em que se encontra Cleo durante o filme: inanimada, inexistente, sem poder falar ou agir, pois está morta. Ao menos morta, no entanto, não será usada para o trabalho pesado que lhe é imposto. Ao mesmo tempo, é possível pensarmos: morta, permanece como um mito, como as figuras folclóricas mexicanas. Nunca humana.

\footnotetext{
${ }^{8}$ Artigo originalmente publicado na revista Civilização Brasileira, n. 3, em 1965. Disponível em: <https://movimentorevista.com.br/2018/08/uma-estetica-da-fome-glauber-rocha/>. Último acesso em: $30 \mathrm{dez}$ 2019.
} 
María Lugones (2014) complexifica a noção de colonialidade do poder de Quijano ao elaborar o que define como colonialidade de gênero, o que seria uma "análise da opressão de gênero racializada capitalista (LUGONES, 2014, p. 941), na intenção de

\begin{abstract}
nomear não somente uma classificação de povos em termos de colonialidade de poder e de gênero, mas também o processo de redução ativa das pessoas, a desumanização que as torna aptas para a classificação, o processo de sujeitificação e a investida de tornar o/a colonizado/a menos que seres humanos. (LUGONES, 2014, p. 939)
\end{abstract}

Para Lugones, o processo de redução ativa das pessoas e a dicotomia entre o humano e o não humano são centrais no pensamento moderno colonial e se tornaram ferramentas normativas utilizadas para dominar os colonizados(as). A modernidade funciona a partir da classificação das pessoas e organização do mundo a partir de categorias homogêneas, atômicas, separáveis e puras, sendo assim, para que se possa construir uma crítica e uma análise feminista e interseccional, Lugones sustenta que deve-se ir além do universalismo e da lógica categorial moderna. A pureza categorial funciona definindo cada categoria em referência ao seu membro herarquicamente superior. Assim, a categoria "mulheres" refere-se à mulher branca, assim como a categoria "negros" é construída em referência ao homem negro, "indígena" ao homem indígena e "pobre" ao homem pobre, não estando estas categorias articuladas para incluir mulheres negras/indígenas/mestiças e pobres no pensamento e nas instituições modernas. Quando se tenta, então, compreender as mulheres na intersecção entre raça, classe e gênero, as mulheres não brancas, na análise de Lugones, são seres impossíveis. São impossíveis porque não são mulheres brancas ou homens de cor e, por isso, quando pensamos nessa intersecção, o que ela nos revela é a ausência das mulheres negras, indígenas, mestiças e de cor do pensamento moderno e não sua presença. Compreender essa impossibilidade é especialmente necessário ao analisarmos a representação dessas mulheres nos meios de comunicaçação e na arte, pois é também a partir deles que estas ausências se tornam palpáveis ${ }^{9}$ e profícuas para a crítica à colonialidade de gênero.

O silêncio de Cleo e sua ausência enquanto sujeito narrativo revela sua impossibilidade, pois ela é construída a partir desse paradigma, seja propositalmente pela crítica que o filme pretende propor ou como resultado do embricado de estruturas sociais que a produzem como tal. Por vezes a personagem funciona como parte da casa, como um objeto ou uma força inerente a ela, movimentando-se no quadro sem chamar atenção para si, como

\footnotetext{
${ }^{9}$ Sobre isso, é necessário destacar que Yalitza Aparicio, atriz que interpreta Cleo em Roma é a primeira mulher indígena indicada a melhor atriz no Óscar e a segunda mexicana a concorrer na categoria nos 90 anos da premiação. Antes dela, Salma Hayek foi a primeira atriz mexicana indicada em 2002 pela interpretação em Frida (Julie Taymor, 2002).
} 
se efetivamente fosse invisível e não existisse ali enquanto sujeito narrativo. A câmera movimenta-se em panorâmicas onde a casa parece ser o personagem principal, não Cleo, que apenas passa pelo quadro cumprindo seus afazeres (figura 6).

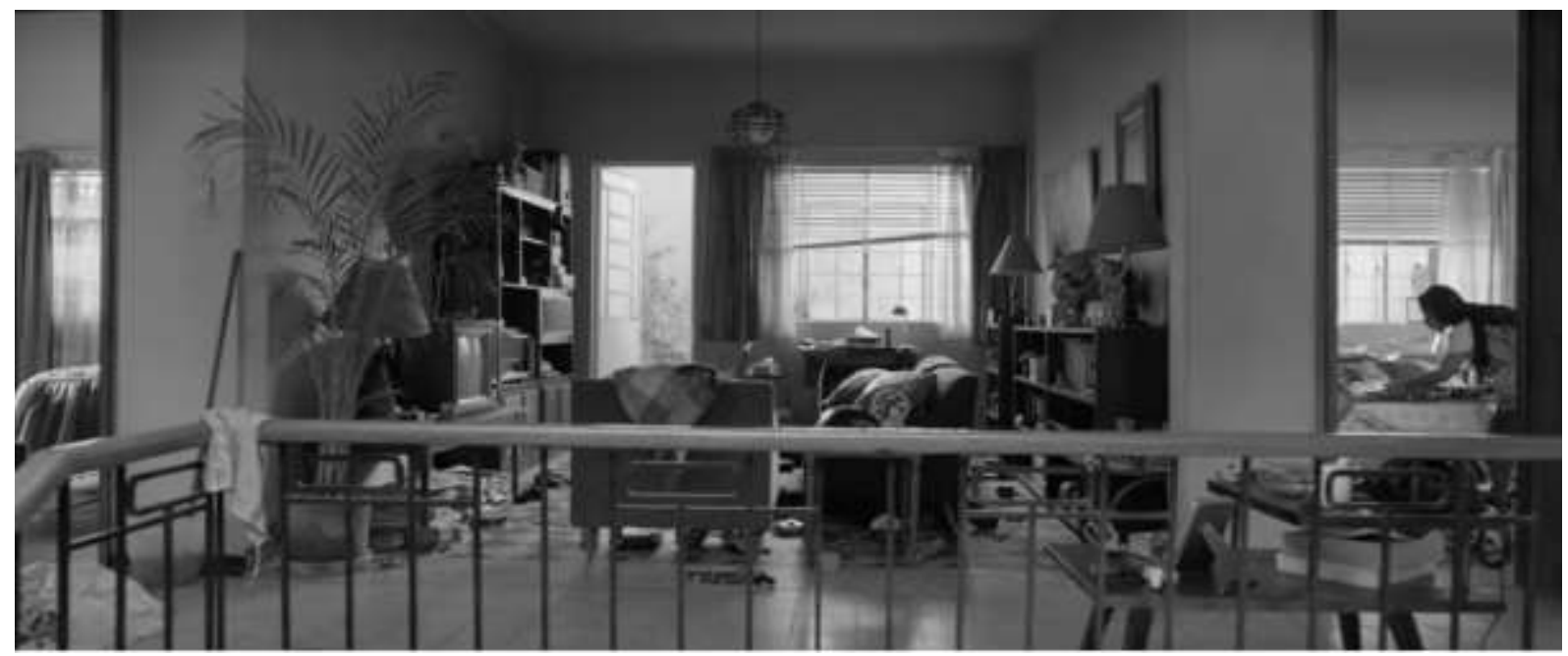

Figura 6 - Cleo ao fundo do quadro arrumando o quarto, enquanto a câmera realiza uma parorâmica. Fonte: Captura de dela do filme

O distanciamento narrativo na representação de Cleo fica visível nas escolhas estéticas do filme, na impessoalidade dos planos conjuntos, na grande profundidade de campo que uniformiza o ponto de vista, se distanciando da subjetividade. A câmera efetivamente desprende-se de Cleo, que sai e entra de quartos, desce escadas, aparece e desaparece, nunca ocupando um lugar próprio no quadro nem conduzindo a movimentação da câmera. Cleo é reduzida novamente a sua condição de uso, de propriedade e de não humana, portanto impossível enquanto sujeito e enquanto personagem. Permanece em quadro não enquanto sujeito/personagem, mas enquanto mito.

E é a mitologia em Cleo que se demonstra nos poucos momentos em que a câmera solidifica sua condição de personagem. Primeiro, na figura da empregada que lava incessantemente a sujeira que também incessantemente se produz, seja no pátio, lavando o chão, seja no terraço, lavando roupas. Numa tomada geral, Cleo se transforma num conceito, pois a câmera mostra tantos outros terraços com tantas outras empregadas lavando e estendendo roupas. Num segundo momento, Cleo representa a figura da mulher em sua condição reprodutiva: é objeto de desejo sexual para Fermín e, depois, é abandonada grávida no cinema. Na cama, diante do espetáculo patético de um rapaz que exibe suas habilidades nas artes marciais nu, no quarto do motel, ou no centro do olhar da câmera, deixada sozinha pelo mesmo Fermín, que acada de saber de sua gravidez. A câmera se orienta por Cleo novamente na longa tomada de seu parto, o que sedimenta a construção de sua personagem enquanto sofrimento. Enquanto "sofre" um parto, passiva, olha seu bebê, a quem a equipe do 
hospital tenta reanimar, sem sucesso. Por todo o processo, a câmera parece querer tomar cada momento possível do auge desse sofrimento.

Na fotografia de Cuarón (o diretor é, também, quem faz a cinematografia de Roma), Cleo será o centro da narrativa da câmera mais duas vezes, de modo que se feche o arco no qual o diretor propõe esta mulher como mito. Quando, depois de perder a filha, é enquadrada de costas e depois de frente, recortada pelo marco da porta de seu quartinho, inerte, porém sem poder guardar seu luto de forma adequada (figura 7), Cleo é descrita como o próprio totem ao sofrimento que representa, como que uma Pietá de Michelângelo, porém sem a criança nos braços.

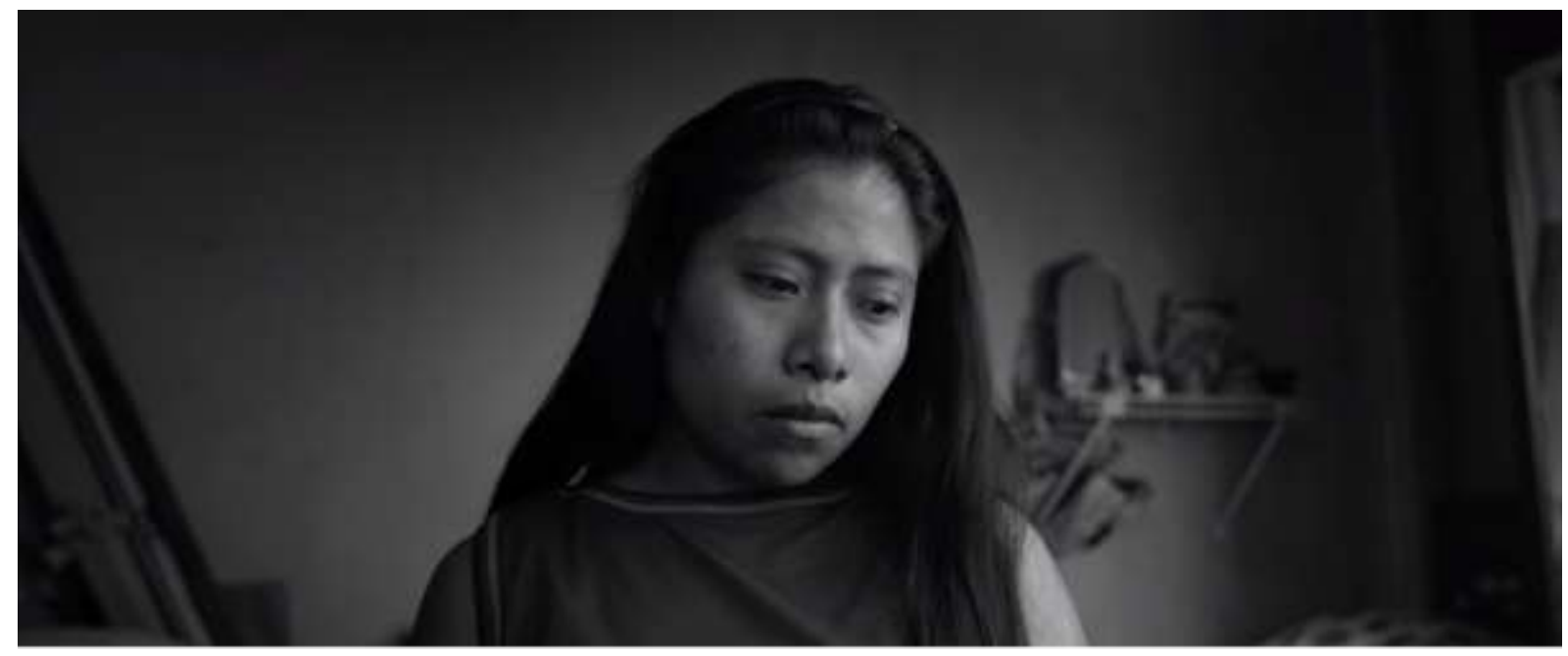

Figura 7 - Cleo após a morte da filha. Fonte: Captura de dela do filme

A mitologia desta mulher termina de ser erigida na sequência em que salva duas crianças do afogamento, ainda que não saiba nadar. A câmera faz o percurso até as ondas ao seu lado, numa bucólica construção contra o sol que já quase se põe, recortando as quase silhuetas dos personagens, e depois a enquadra no ápice dramático da cena, quando retorna à areia e se vê entrar em quadro Sofia, a mãe das crianças, que a abraça e agradece por salvar seus filhos. É dolorosa a dinâmica que esse ciclo se fechando produz, já que Cleo é aquela que fornece o calor afetivo de uma mãe a crianças que não são suas filhas (o que faz durante toda a narrativa) e, sofrendo por não ter conseguido salvar a própria filha (e pela culpa de não ter desejado que ela nascesse), arrisca a própria vida para salvar os filhos da patroa Sofia. A imagem que Cuarón cristaliza é a da mãe enquanto um conceito, a mãe judaico-cristã, que além de tudo é um corpo de uso, uma humanidade impossível cujo valor se desenha quando sacrifica sua cultura, seu idioma, seu lugar no povoado e até seu afeto maternal pelos que detém a palavra, o discurso histórico, a câmera. É como se Cuarón dissesse que não fosse por 
Cleos, algumas crianças não chegariam a ser grandes nomes da cinematografia mundial (ou da ciência, ou da literatura, etc.).

\section{A babá de Cuarón e o olhar como poder}

Colonizar é coisificar, é tornar inumano, considere-se raça, classe social ou sexo. O exercício dessa coisificação fica a cargo de um sistema que tem seus instrumentos e suas técnicas, e é um processo discursivo de dinamização do poder. A câmera, como se nota pelas considerações da seção anterior, é um poder, é um lugar, é um discurso, pois é o instrumento de um olhar. Façamos aqui uma analogia, tomando gênero, raça e classe, como o tripé da opressão que representam, como categorias da colonialidade, para então tomarmos o que postula Teresa de Lauretis (1987) aplicável também às condições étnico-raciais e socioeconômicas. Assim, "[o gênero] é produto de várias tecnologias sociais, como o cinema, assim como discursos institucionais, epistemologias, e práticas críticas; por isto querendo dizer não apenas a crítica acadêmica, mas práticas sociais e culturais mais abrangentes" (LAURETIS, 1987, p. ix). A tecnologia de gênero é dinamizada no interior de um dispositivo que toma em consideração o poder circunstancial, que é o que Michel Foucault (1988) estabeleceu para sua "tecnologia do sexo" enquanto algo que surge como um conjunto de técnicas que tem como objetivo a sobrevivência e hegemonia de uma classe (para Foucault, a burguesia). Roma, e o próprio retrato em preto e branco da babá da infância de Cuarón, é um discurso sobre o sofrimento de Cleo como representação de uma figura comum na América Latina, especialmente nos países de língua espanhola, que é a própria síntese da tríade de opressões. Cuarón quer representar uma jovem heroína através de seu silêncio e subserviência. Quer representar o afeto através de uma abnegação judaico-cristã, mitológica e inúmeras vezes descrita na grande narrativa da fundação da civilização ocidental. A coragem ou a força de Cleo vem de um imaginário onde é construída, mulher, não branca e pobre, como um instrumento, como sofrimento, como alguém que é definido pela sua luta por sobreviver e, acima de tudo, por "servir a um bem maior", qual seja: o progresso das classes hegemônicas. Assim, é possível ver no olhar enquadrado de Cuarón, para além de uma homenagem que se faz na denúncia de uma opressão, uma romantização que constrói Cleo não como humana, como igual, mas como uma categoria, coisificada através de sua instrumentalização, desumanizada pelo próprio ato de ser transformada em algo para o que ou para quem.

Não é confortável, certamente, dessensibilizar-nos com a homenagem do diretor a alguém por quem guarda uma memória afetuosa, porém o olhar decolonial, assim como o 
feminista, nos obrigará a um deslocamento a partir de onde é prioritária a busca de um olhar que não seja o do colonizador. "Porque as mulheres foram uma população colonizada por tanto tempo, temo que qualquer categoria crítica que possamos achar aplicável hoje é provavelmente derivada de ou imbuída com ideologias masculinas” (LAURETIS, 1987, p. 84). A tecnologia discursivo-ideológica que o audiovisual é responde a um programa, codificado na visão hegemônica que nos é apresentada como um neutro. Nesse programa, as mulheres - e as não brancas e pobres, especialmente, em que pese a já mencionada tríade opressiva - são discursivamente construídas como imagem e, portanto, como objeto. A socialização ocidental nos conduz a um olhar que, mesmo afetuoso ou mesmo que parta de um lugar que se propõe crítico ou, ainda, objetivamente daqueles que são oprimidos, produz discursos que reiteram a lógica e o programa do sistema. Ann Kaplan (1995) faz uma análise sobre "Hollywood" que nos serve - já que Cuarón é um diretor mexicano, porém faz parte do panteão dos aclamados diretores de cinema atualmente. Para Kaplan, Hollywood está carregada de uma ideologia patriarcal, construindo a mulher de modo a refletir as necessidades e o inconsciente do patriarcado. Podemos dizer que esse patriarcado é análogo da lógica capitalista e colonial, o que nos ajuda a compreender o olhar reproduzido em Roma como um discurso que deixa nos interstícios seu lugar.

Ao ser afetuoso com Cleo, o filme também é condescendente, e portanto paternalista e, assim, coisifica a pessoa, ainda que na forma de um mito. Assim como o uso da imagem da mulher como musa pelos pintores e poetas, a romantização da sofrida e abnegada Cleo parece render a quem representa uma homenagem caridosa, sensível e admiradora. A verdade é que a mitologização e/ou romantização das mulheres e/ou mães e/ou povos originários ("primitivos") os torna inumanos, unidimensionais, corpos de uso, "verdades" obtusas contadas pelo discurso narrador de terceiros (os que tem o poder sobre a narrativa). O caráter político do olhar, como reforça Laura Mulvey (1989) em Afterthoughts on "Visual Pleasure and Narrative Cinema" representa essa faceta das narrativas cinematográficas, que são construídas por olhares hegemônicos, de lugares de poder. Ainda que Cuarón possa propor uma narrativa onde Cleo é resultado de uma memória afetiva e ao mesmo tempo encerre em si a síntese do que o colonizado representa enquanto tal, o discurso audiovisual em Roma demonstra a socialização de um colonizador, homem, branco e de uma elite econômica.

Roland Barthes (2001), em Mitologias, ao dizer que o mito é uma fala, está fundamentando uma teoria sobre o discurso, especialmente se pensarmos sobre quais são os mitos fundantes de nossa civilização ocidental. Nos valemos de Carl Jung (2013) também quando entendemos que o mito é uma manifestação dos arquétipos do inconsciente. “[...] $\mathrm{O}$ 
outro, seja qual for, é reduzido ao mesmo. [...] O outro é transformado em puro objeto, espetáculo, marionete [...]." (BARTHES, 2001, p. 171-172) O "outro" de quem fala Barthes aqui é o outro para o pequeno burguês - onde podemos colocar tanto os pobres quanto os povos colonizados - e é o mesmo "Outro" da concepção de Simone de Beauvoir (2009), pois que a mulher é definida em sua relação com o homem.

[...] A função do mito é transformar uma intenção histórica em natureza, uma contingência em eternidade. Ora, este processo é o próprio processo da ideologia burguesa. [...] O que o mundo fornece ao mito é um real histórico, definido [...] pela maneira como os homens o produziram ou utilizaram; e o que o mito restitui é uma imagem natural deste real. (BARTHES, 2001, p. 162-163, grifo no original)

Assim, o patriarcado define a natureza da mulher como subserviente, como o capitalismo e a colonialidade definiu seus outros como abnegados, pueris, simplórios e, acima de tudo, valorados pela "sua capacidade" de sacrificar-se pelos seus superiores. O valor que marca a memória do menino da classe média branca mexicana que foi Cuarón sobre a babá é sua capacidade infinita de deixar-se de lado, mesmo no cansaço, no abandono, na violência e na dor, para ser afetiva, útil e resiliente. Sua coragem romantizada salva os filhos do patrão ainda no luto da própria filha natimorta. $\mathrm{Na}$ romantização de Cleo, o olhar de Cuarón a transforma em imagem como em coisa. O "outro" é imagem pois inumano, impossível e passivo, e o discurso que romantiza, mitologiza, é o naturalizador de condições que lhe são impostas, não raro com violência. É nessa acepção que usamos imagem, o que também nos conduz à noção de uma estética. "A mulher é, antes de tudo, uma imagem. [...] A mulher é feita de aparências. [...] Códigos bastante precisos regem suas aparições assim como as de tal ou qual parte de seu corpo." (PERROT, 2017, p. 49-50) A estética, diz Perrot, é uma ética. A Cleo da memória e da construção discursiva de Cuarón carrega a ética da posição de quem detém o poder do olhar. Aqui, acima de tudo, um olhar que é ativo sobre um (não-)sujeito que é passivo.

A mulher é vista como imagem, eis também um modo de matar outra coisa que ela possa ser, sobretudo seu potencial político. [...] emblemática do que é a história dos homens, símbolo da aniquilação pela qual se alcança na história e na experiência dos homens que a constituiu o absoluto do gozo escópico em que o olho se torna o órgão devorador do mundo, com toda a carga de efeitos e ressonâncias suspeitáveis em termos políticos [...]. (TIBURI, 2010, p. 304-5)

A própria imagem de Sofia, a patroa, mãe das crianças e esposa abandonada, é um mito. Ela existe na história como representante pouco simpática de uma categoria de mulheres que vive a intersecção de uma circunstância de opressões. Branca e de classe média, essa mulher nos é apresentada como um ser vazio, que só existe na ambivalente relação com as empregadas (de quem depende e a quem trata com certo paternalismo e muitas vezes com 
hostilidade) e na dependência afetiva quase doentia do marido. À sua maneira, Sofia também é um personagem impossível, pois é construída apenas na sua capacidade de sobreviver à opressão patriarcal e ao abandono masculino e existe narrativamente apenas pelo sofrimento.

Sofia é construída por um olhar que tende a demonstrar uma certa vergonha pelo seu papel de colonizadora sobre Cleo - uma espécie de reparação, já que Cuarón está representando nela o que seria sua mãe, ainda que ficcionalizada. Ao chegar em casa embriagada após se dar conta que o abandono do marido é real, Sofia fala para Cleo, em uma das poucas vezes em que dialoga com ela sem que seja para pedir que realize alguma tarefa: "Não importa o que te digam, nós, mulheres, estamos sempre sozinhas." Ainda que estejam, de fato, ambas as personagens sozinhas enquanto mulheres presas na sua condição (de mulher e de mãe) e que o filme tenha procurado aproximá-las por essa condição, a solidão experienciada por Cleo tem contornos e lugares muito distintos da de Sofia, o que é evidente até mesmo na possibilidade que ela tem de sair para beber, destruir o carro do marido e extravasar a raiva frente a sua situação enquanto processa as opressões das quais está submetida. Para Cleo, o imperativo do trabalho faz com que não tenha nem tempo e nem espaço para processar as múltiplas opressões que a atingem. A maneira com que o filme narra Sofia nos conduz a uma espécie de desprezo por ela, que é, também, uma mulher e, como tal, sobrevive a um sistema que lhe é hostil também. Abandonada de maneira vil, assediada pelo compadre que lhe vê como um objeto sem dono, Sofia se vê obrigada a carregar todas as obrigações nas costas, porém é nessa circunstância que se percebe que o marido era ausente como tal e como pai, e é narrado, nesses dois papéis, como um mito agora proposital e a ser destruído.

A masculinidade é desenhada pelo olhar de Cuarón no contraste com as mulheres. Os meninos brincam e brigam de modo que demonstrem sua ritualizada relação com a violência. São infantis e refletem uma socialização insensibilizadora. O jovem Fermín, pai do bebê de Cleo, representa uma ritualística masculina bem encaixada em um universo grandiloquente e "mágico". Imagina-se um futuro lutador de artes marciais, e sua demonstração de virilidade diante de Cleo é uma ridícula dança na qual se faz maior e mais importante do que é - quando não passa de uma versão de mais idade do filho mais velho da família para quem trabalha Cleo. Numa sequência emblemática, Cleo, com gravidez aparente, viaja até o povoado onde mora Fermín para reafirmar sua condição. Encontra patéticas demonstrações de uma megalomania que é, a um só tempo, colonizada e reiteradora de uma socialização que não amadurece os homens. Fermín está junto de uma dezena de outros jovens fazendo um treinamento na arte marcial oriental que tem como guru um homem que fala e se porta como 
se fosse uma deidade. $\mathrm{O}$ homem parece ser a síntese de um lutador de lucha libre, um mestre de karatê e um ilusionista caricato de circo. Ele propõe o que parece ser um exercício de extrema destreza e dificuldade, e os jovens, assim como as pessoas que assistem ao redor, tentam, sem sucesso, imitá-lo. Somente Cleo consegue, o que representa uma espécie de naturalização da mulher como alguém capaz das façanhas mais absurdas, mesmo grávida, em oposição à inépcia dos homens. Minutos depois, Fermín dá de ombros para a notícia de que Cleo espera um filho seu, ameaçando-a com um gestual de luta e gritos desproporcialmente exagerados em frente à uma mulher que assiste ao desprezo violento do pai de sua filha de forma apática e acuada. Por fim a chama de "faxineira de merda", com isso desprezando Cleo duas vezes: por sua condição de mulher e por sua condição de classe.

Dr. Roberto, “o patriarca”, tampouco é construído de forma simpática. Da primeira vez que aparece no filme, é antecipado por um conjunto de ações que parecem refletir sua mitologia diante da família e dos empregados, que assistem a sua chegada admirados e saudosos. Primeiro ouvimos a buzina insistente diante do portão da garagem, depois a montagem de vários planos de detalhe - raros no filme - que ora mostram sua mão empunhando ao mesmo tempo o cigarro e o câmbio do carro. Os planos detalham o ritual no qual o pai da família manobra cuidadosamente um carro enorme para que entre na garagem sem arranhar a lataria. Essa sequência é acompanhada por música erudita, épica, e diegética pois é executada pelo toca-fitas do carro. O pai da família é assim anunciado ao espectador como um mito distante e sujeito a ser destruído de masculinidade e paternidade tradicionais, fazendo-se ridículo, frívolo e arrogante.

O paradigma da modernidade, oculto por trás do discuso do progresso, do conhecimento e do avanço científico, é o desperdício da vida humana, a redução ativa das pessoas para que, desprovidas da complexidade que envolve sua existência, sirvam com complacência aos prósitos do sistema mundo que se constituiu e vem se constituindo desde o período colonial. Para funcionar, esse sistema necessita tanto da redução das pessoas a meros objetos de uso, como da docilidade com que desempenharão este papel. Para que se realize o trabalho doméstico de manutenção da vida e o trabalho da maternidade, é necessário que se concretize ambas as condições. A impossibilidade de Cleo e de sua representação enquanto figura fílmica e o esvaziamento de Sofia, ambos se dão, talvez, por conta da nossa dificuldade em superar a lógica categorial moderna colonial/patriarcal e suas estruturas de poder enquanto sociedade, assim como também no lugar hegemônico de detentores do poder da narrativa. 


\section{Referências}

BARTHES, Roland. Mitologias. Rio de Janeiro: Bertrand-Brasil, 1989.

BEAUVOIR, Simone de. O segundo sexo. 2a ed. Tradução de Sérgio Milliet. Rio de Janeiro: Nova Fronteira, 2009.

FEDERICI, Silvia. Calibã e a bruxa: mulheres, corpo e acumulação primitiva. Tradução: coletivo Sycorax. São Paulo: Elefante, 2017.

FOUCAULT, Michel. História da Sexualidade I: A vontade de saber. Rio de Janeiro: Edições Graal, 1988.

JUNG, Carl G. Os arquétipos do inconsciente coletivo. Petrópolis/RJ: Vozes, 2013.

KAPLAN, E. Ann. O olhar é masculino? In: A mulher e o cinema. Os dois lados da câmera. Tradução: Helen Marcia Potter Pessoa. Rocco: Rio de Janeiro, 1995. p. 43-60.

LAGARDE, Marcela y de los Rios. Los cautiverios de las mujeres: madresposas, monjas, putas, presas y locas. Colección Posgrado, $4^{\mathrm{a}}$ ed. México, D.F: Universidad Nacional Autónoma de México, 2005.

LAURETIS, Teresa de. Technologies of Gender: Essays on Theory, Film, and Fiction. Bloomington: Indiana University Press, 1987.

LUGONES, María. Rumo a um feminismo descolonial. Estudos Feministas, Florianópolis, 22(3):320, set-dez/2014, p. 935-952.

MIGNOLO, Walter D. COLONIALIDADE: O lado mais escuro da modernidade. Revista Brasileira De Ciências Sociais, Vol. 32 n 94 junho/2017, p. 1-18. Disponível em: http://www.scielo.br/pdf/rbcsoc/v32n94/0102-6909-rbcsoc-3294022017.pdf . Último acesso em: 30 dez. 2019.

MULVEY, Laura. Afterthoughts on 'Visual Pleasure and Narrative Cinema' inspired by King Vidor's Duel in the Sun (1946). In: . Visual and Other Pleasures. Language, Discourse, Society. Londres: Palgrave Macmillan, 1989. p. 29-38.

PERROT, Michelle. Minha história das mulheres. São Paulo: Contexto, 2017.

QUIJANO, Aníbal. A colonialidade do saber: eurocentrismo e ciências sociais. Perspectivas latino-americanas. Edgardo Lander (org). Coleccin Sur Sur, CLACSO, Ciudad Autónoma de Buenos Aires, Argentina, 2005. P. 107-130.

QUIJANO, Aníbal. Colonialidade do Poder e Classificação Social. in: SANTOS, Boaventura. MENESES, Maria Paula (org). Epistemologias do Sul. Almedina, Coimbra, 2009, p. 73-117.

ROCHA, Glauber. Uma Estética da Fome. Artigo originalmente publicado na revista Civilização Brasileira, n. 3, em 1965. Disponível em:

https://movimentorevista.com.br/2018/08/uma-estetica-da-fome-glauber-rocha/. Último acesso em: 30 dez 2019. 
TIBURI, Márcia. Ofélia morta - do discurso à imagem. Revista Estudos Feministas, Florianópolis, v. 18, n. 2, p. 301-318, maio-agosto de 2010. Disponível em:

<http://dx.doi.org/10.1590/S0104-026X2010000200002>. Último acesso em: 30 dez 2019. 